\title{
Molecular Genetics and Fetal Brain
}

\section{Ana Stavljenic-Rukavina}

Correspondence: Professor Ana Stavljenic-Rukavina, MD,PhD, Chamber of medical biochemists, Zagreb, Croatia

E-mail: astavljenic@ hkmb.hr

\begin{abstract}
M olecular aspects of genetic diseases that affect the nervous system are in the focus of scientific interest investigators from many fields of medicine and the knowledge of genetic abnormalities as well as phenotypic heterogeneity is rapidly expanding. This review is aimed to provide clinician's practical insight into molecular aspects of certain brain abnormalities and disorders based on prenatal ultrasound assessment and clinical findings. A dditionally some risk determinants are included in order to elucidate its contribution to molecular mechanism underlying the disease development. M aking a specific diagnosis of a genetically determined neurological disorder or defects requires access to a laboratory that can assist in arranging for appropriate testing to be carried out. Therefore this review contains technological aspects of molecular genetic testing, international guidelines and policies related to genetic testing and recommendation for application in clinical medicine.
\end{abstract}

Keywords: Fetal brain, molecular mechanism, chromosomes, DNA, $\mathrm{PCR}, \mathrm{FISH}$

\section{INTRODUCTION}

The recent investigations of fetal brain development based on prenatal brain imaging by ultrasound (US) or magnetic resonance imaging (MRI) have suggested that anatomical defects are manifested as functional defects and have one or more specific genetic background. ${ }^{1}$ Over past 15 years the molecular bases for thousands single gene disorders have been examined and characterized improving diagnosis, particular prenatal diagnosis. Furthermore new technological advances in sampling and nanotechnology assays for analysis of chromosomes, DNA or RNA have opened to clinicians new window and large capacities for accurate diagnosis. A mong other the most sensitive diagnostic needs are those for an early recognition of brain damage caused by genetic and other factors which might influence the fetus growth and development or disturb quality of children life. Recently it was found that fetal behavior, particularly facial expression, assessed by advanced 4-D sonography and defined by neurological scoring test (K urjak at all) reflects the activity of fetal central nervous system continuously from fetal to neonatal life. The application of both, genetic examination and the study of facial expression may be of additional diagnostic value in prenatal medicine as well as useful tool in basic research of fetal brain. This review brings together main bibliographic data on molecular genetics of certain brain disorders based on prenatal ul trasound assessment and clinical findings. A dditionally some risk determinants are included in order to elucidate its contribution to molecular mechanism underlying the disease development. The review contain furthermore technological aspects of molecular genetic testing and EU recommendation for its application in clinical medicine.

\section{MOLECULAR GENETIC ASPECTS OF MOST COMMON ULTRASOUND FINDINGS: GENOTYPE VS PHE NOTYPE}

Miarocephaly is defined as condition where the circumference of the head is more than two standard deviations smaller than average for fetus or child age and sex. It may be congenital or it may develop in the first few years of life. Microcephalic phenotype is characterized for a larger group of neurogenetic syndromes described and named according to different authors. Beside genetic factors microcephaly may also be associated with maternal problems such as alcohol consumption (fetal alcohol syndrome disability), diabetes, or rubella infection. The disease is characterized by neurological defects, impaired intellectual development and small brain caused by the disturbance in the proliferation of nerve cells. Infants with microcephaly are born with either a normal or reduced head size. Subsequently the head fails to grow while the face continues to devel op at a normal rate, producing a child with a small head and a receding forehead. Development of motor functions and speech may be del ayed. Hyperactivity and mental retardation are common occurrences, although the degree of each varies. Convulsions may al so occur. M otor ability varies, ranging from clumsiness in some to spastic quadriplegia in others. The disturbances in motor functions appear later in life.

Primarily genetic background was found and is caused by non functional mutation in one of the six microcephalin genes (MCP H 1 to M CP H 6) which causes the loss of their function. 2,3 The autosomal recessive inheritance is caused by the deletion in regions listed below on Table 1. 
Table 1: Microcephalin gene mutations

\begin{tabular}{ll}
\hline Microcephalin gene & Mutation \\
\hline MCPH1 & $8 p 23$ \\
MCPH2 & $19 q 13.1-13.2$ \\
MCPH3 & $9 q 33,3$ \\
MCPH4 & $15 q 15-21$ \\
MCPH5 & $1 q 31$ \\
MCPH6 & $13 q 12.2$ \\
\hline
\end{tabular}

Some of microcephalic syndromes are associated more with intellectual and developmental delay, sleep disturbance, seizures, jerky movements especially hand-flapping, frequent laughter or smiling, and usually a happy demeanor (A ngelman syndrome). It is a classic example of genetic imprinting that it is usually caused by deletion or inactivation of genes on the maternally inherited chromosome 15 (M CPH4). The sister syndrome, Prader-W illi syndrome, is caused by a similar loss of function of paternally-inherited genes (chromosome 15q partial deletion). 4,5

$\mathrm{M}$ icrocephalia is furthermore associated with deletion of $1 p 36,3 p, 4 p, 5 p, 18 p, 11 q, 18 q, 22 q 11.2$, and duplication in 10q. In microcephalic individuals mutations in the ERCC 6 and ERCC 8 genes was fund to cause Cockayne syndrome. The proteins made by the ERCC 8 and ERCC 6 genes are responsible for repair of damaged DNA by the transcription-coupled repair mechanism, particularly the DNA in active genes. If either the ERCC 6 or the ERCC 8 gene is al tered, DNA damage can not be repaired. The autosomal dominant type of this disorder might result from deletions or new mutations in SMADIP 1 gene on chromosome $2 q 22 .{ }^{6}$ On the other hand in some of affected individuals abnormalities of this gene were not currently detectable thus all owing to speculate that even some other genes might be affected leading to the same phenotype.

Other clinical syndromes as Hirschsprung disease, microcephaly, mental retardation, and characteristic facial features have been identified showing genetic changes on a locus at chromosome $2 \mathrm{q} 22-\mathrm{q} 23{ }^{7}$

Smith-Lemli-O pitz syndrome is disorder inherited in an autosomal recessive pattern, which means mutations of D HCR 7 gene. ${ }^{8}$ The DHCR 7 gene is responsible for production of an enzyme called 7-dehydrochol esterol reductase. This enzyme is responsible for the final step in the production of cholesterol which is an essential nutrient necessary for normal embryonic devel opment. Cholesterol is al so a structural component of cell membranes and the myelin. A dditionally, cholesterol plays an important rol e in the production of steroid hormones. M utations in the DHCR7 gene reduce or eliminate the activity of 7-dehydrocholesterol reductase, preventing cells from producing enough cholesterol. As a consequence of loss in enzyme activity potentially toxic byproducts of cholesterol production accumulate in blood and other tissues. The combination of low cholesterol levels and an accumulation of toxic byproducts likely disrupts the growth and development of many body systems in Smith-L emli-O pitz syndrome.

In the review on the development of the cerebral cortex progresses through defined stages including neural proliferation, neuroblast migration and neuronal differentiation L ian presented potential causative genes responsible for underlying mechanism for many of syndromes which are presented as microcephalic phenotypes. $^{9}$

In a number of other syndromes belonging into microcephalic phenotypes no recognized genetic marker for more specific differential diagnosis is confirmed as yet.

Craniosynostosis is characterized by an early closing of some or all of the sutures in the skull of an infant or child causing problems with normal brain and skull growth.

It can result in craniostenosis, the skull deformity caused by the premature closure of the cranial sutures and increased intracranial pressure (Fig. 1). A s in microcephalia about 20\% of cases are associated with particular syndromes characterized by the presence of a variety of features, signs, and symptoms throughout the body. Genetic test is available to confirm the diagnosis of only one specific syndrome called FGFR-3 associated coronal synosthosis syndrome. ${ }^{10,11}$ The main problem in differential genetic diagnosis is a variety of new mutations occurring in fibroblast growth factor receptor gene (FGFR 1,2,3) transforming growth factor beta receptor I (TGF $\beta 1$ ) twist transcription factor and fibrillin 1 (FBN 1 ) in different syndromes. $\mathrm{N}$ ew mutations may be present even if there is no family history of the disorder. ${ }^{12,13}$

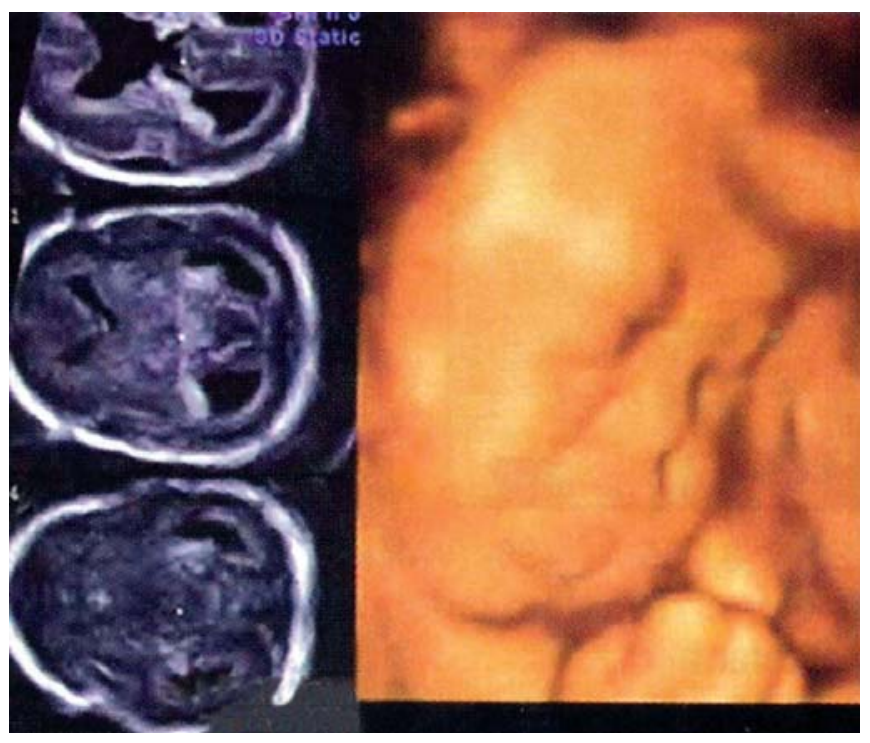

Fig. 1: Ultrasonic image of craniosynostosis (with permission, courtesy Dr. Pooh) 
However, there are over 150 syndromes associated with craniosynostosis. ${ }^{6}$ The most common causes of syndromic craniosynostosis are Crouzon syndrome and Apert syndrome for which molecular diagnostics is not available up to know. There is an extended list of all symptoms that could occur within each syndrome but at the same time considerable overlap of symptoms between many of these syndromes is present. Therefore for differential diagnosis clinical evaluation of genetic test findings by a geneticist is ultimate.

\section{Mic rognathia}

Ultrasound expression of micrognathia is associated with more than 40 different syndromes which are rare and all of them is not defined as genetic disorders by evidence based scientific principles (EBM) (Fig. 2). A number of studies and reports bring number of data on potential molecular mechanism involved in some syndromes, but it is to early for conclusion. Recent investigation of A tel osteogenesis, type 2, a spectrum of skeletal disorders caused by mutations in the solute carrier family 26 (sulfate transporter), member of SLC26A 2 gene brings new genetic insight into molecular mechanism of this syndrome. ${ }^{14}$ Sul phate transporter protein encoded by this gene is essential for the normal development of cartilage and for its conversion to bone. Mutations in the SLC26A 2 gene disrupt the structure of devel oping cartilage, consequently causing lack in bone formation and resulting in characteristic skeletal problems. It is an autosomal recessive disorder. The parents of a affected child are not affected by disorder, but are carriers of one copy of the altered gene. Bloom and Campomelic syndrome

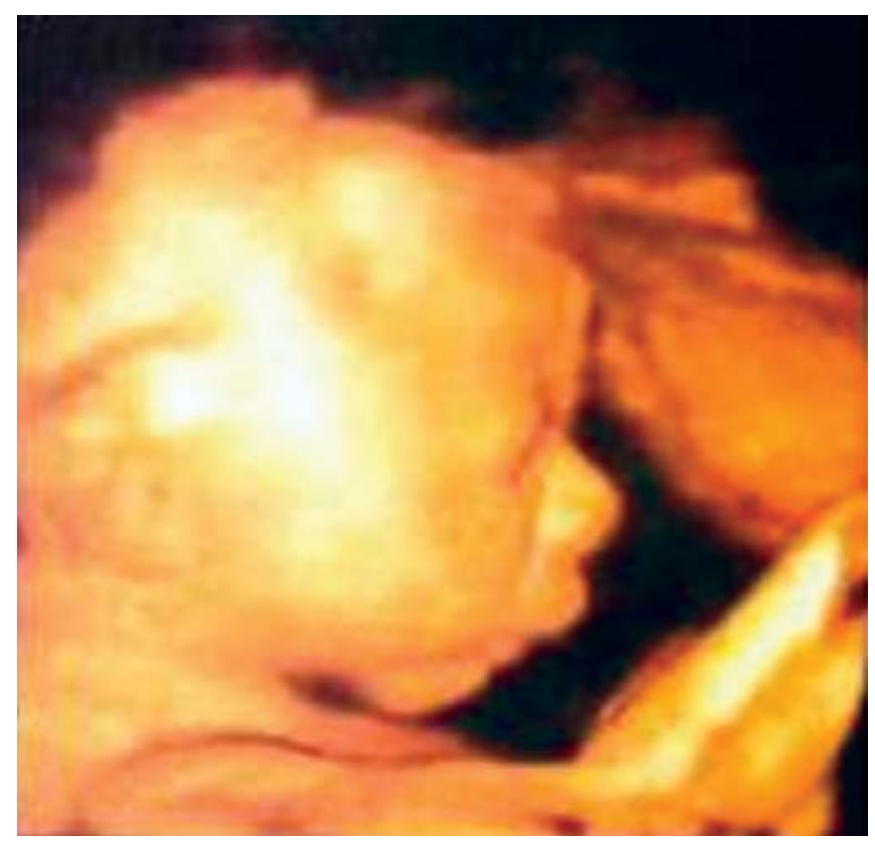

Fig. 2: Micrognathia (courtesy with permission Dr Pooh) were studied extensively. BL M gene located on chromosome $15 q 26$ studied in B loom syndrome and results have shown a large variety of function of BLM gene product and therefore genetic testing is not certain in differential diagnosis of Bloom syndrome. Campomelic dyspasia is an autosomal disease characterized by mutation in SOX 9 gene (sex determining region $Y$ ) localized on chromosome 17 encoding the transcription factor Sox $9 .{ }^{15}$ The protein encoded by this gene recognizes the sequence CCTTGAG along with other members of the HM G-box class DNA-binding proteins. It acts during chondrocyte differentiation and, with steroidogenic factor 1 , regulates transcription of the anti-M ullerian hormone (A M H) gene. Deficiencies lead to the skeletal malformation syndrome campomelic dysplasia, frequently with sex reversal.

Zellweger syndrome is presented on ultrasound examination as micrognathia phenotype too, but because of its other combined fetal anomal ies this syndrome will be presented later.

Anencephaly, cephalic disorder, results from a neural tube defect diagnosed usually by ultrasound between the 23rd and 26th day of pregnancy resulting in the absence of a major portion of the brain, skull, and scalp. ${ }^{16} \mathrm{Children}$ with this disorder are born without a forebrain (Fig. 3), the largest part of the brain consisting mainly of the cerebral hemispheres (which include the isocortex, which is responsible for higher level cognition, i.e. thinking). The remaining brain tissue is often exposednot covered by bone or skin. A nencephaly is part of an emerging class of diseases called cilopathies. The underlying cause may be a dysfunctional molecular mechanism in the primary cilia

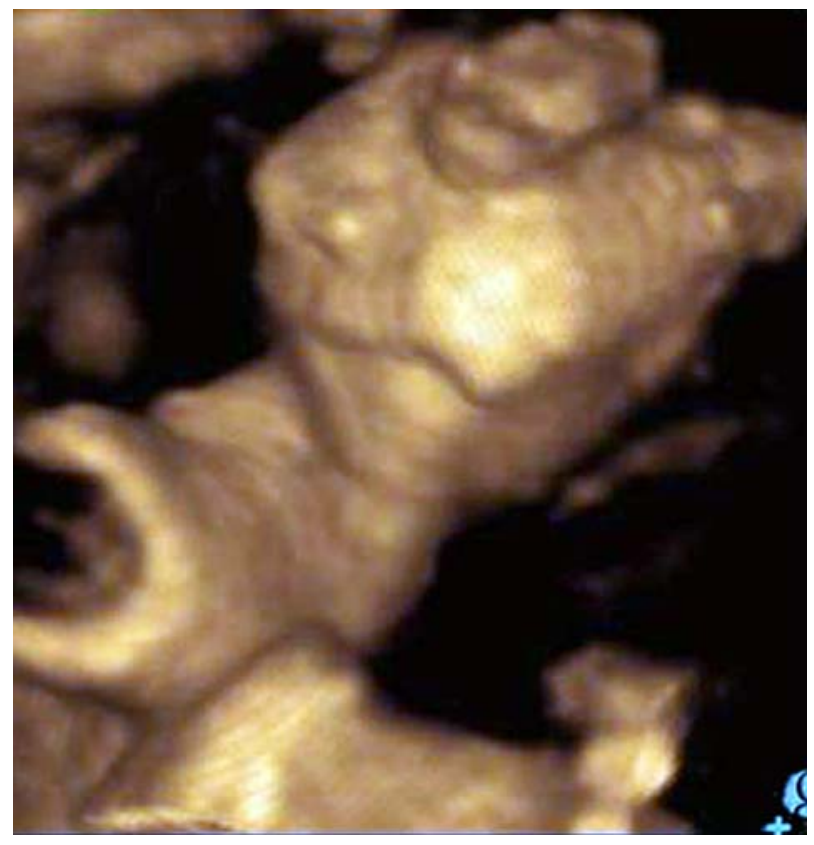

Fig. 3: Anencephaly - sonographic image 
structures of the cell, organelles which are present in many cellular types throughout the human body. The cilia defects adversely affect "numerous critical developmental signaling pathways" essential to cellular development and thus offer a plausible hypothesis for the often multi-symptom nature of a large set of syndromes and diseases.

$\mathrm{N}$ eural tube defect is not recognized as genetic disease jet, but fetal ultrasound and maternal serum al pha-fetoprotein (A FP screening) are standard diagnostic procedures useful for screening spina bifida or anencephaly. ${ }^{16}$ The cause of anencephaly is disputed. N eural tube defects do not follow direct patterns of heredity, though there is some indirect evidence of inheritance Recent animal models indicated a possible association with deficiencies of the transcription factor TEA D 2. ${ }^{17,18}$ Studies in human show that a woman who has had one child with a neural tube defect such as anencephaly, has about a 3\% risk to have another child with a neural tube defect. The risk for anencephaly is associated with certain medication for epilepsy, insul in dependent diabetes, folic acid deficiency, exposure to toxins as lead, mercury and nikel.

\section{MOLECULAR ASPECTS OF COMBINED NEUROLOGICAL AND ORGAN FAILURE DETE CTED BY US OR MRI}

Zellweger syndrome, also called peroxisome biogenesis disorder (PBD) is a rare, genetic disorder (present at birth), characterized by the reduction or absence of peroxisomes in brain, liver and kidney cells. ${ }^{19,20}$ Due to lack of peroxisomes individuals with this syndrome suffer from large metabolic disturbances caused by block in betaoxidation of very long fatty chain acids. Some affected infants may show prenatal growth failure. The brain development and the growth of the myelin sheath are affected due to the fatty covering on nerve fibers in the brain. Symptoms at birth include a lack of muscle tone, an inability to suck and/or swallow, an inability to move. Other symptoms may include unusual facial characteristics, later on mental retardation, glaucoma, seizures, jaundice and gastrointestinal bleeding. The disorder is one of three peroxisome biogenesis disorders which are also known as the Zellweger spectrum (ZS). The other two diseases are neonatal adrenoleukodystrophy (NALD), and infantile Refsum disease (IRD). Molecular and biochemical mechanisms of all three syndromes werestudied extensively and it was found that several peroxins which are coded by PEX genes are associated with Zellweger syndrome, including PEX 1, PEX 2, PEX 3, PEX 5, PEX 6, PEX 12, PEX 14, and PEX 26. M utations in twelve different $P E X$ genes - those that encode peroxins, the proteins required for normal peroxisome assembly - have been identified. Two common PEX 1 mutations have been identified: 1700 fs (in exon 13) and G843D (in exon 15). ${ }^{21,22}$ M utations in PEX 1, the most common cause of Zell weger spectrum disease, are observed in about $68 \%$ of affected individuals. Sequence analysis is recommended for clinical diagnosis for the following seven genes: PEX1, PXMP3(PEX2), PRXR1(PEX5), PEX6, PEX10, PEX12, and PEX26.

Prenatal diagnosis is possible by analysis of DNA extracted from fetal cells if both disease-causing alleles of an affected family member have been identified. Carrier testing is available on a clinical basis once the mutations have been identified in the proband.

Molecular genetic testing is not simple and requires complementation studies. The most common method used is sequence analysis of select PEX 1 exons 13 and 15 To circumvent the need for complementation studies, which require cul tured fibroblasts, two slightly different al gorithms for analysis of a subset of PEX exons have been developed:22

1. Sequence analysis of PEX1 exons 13,15 , and 18, PEX2 exon 4, PEX 6 exon 1, PEX10 exons 3-5, PEX12 exons 2 and 3 , and PEX26 exons 2 and 3 (sensitivity of $79 \%$ ).

2. Sequence analysis of PEX 1 exons 13 and $15, P E X 2$ exon 4 , PEX 10 exons 4 and $5, P E X 12$ exons 2 and 3 , and PEX 26 exons 2 and 3 ( sensitivity of approximately $72 \%$ for the identification of at least one mutation). Testing of the remaining five $P E X$ genes is available on a research basis only.

Prenatal diagnosis is also available by biochemical testing. . $^{2324}$ It is important to confirm the biochemical defects in cultured fibroblasts from the proband, since sometimes the biochemical defects detected in body fluids or liver are not apparent in cultured cells (so-called "peroxisomal mosaicism"). Immunocytochemical analysis of CV S can be used as an adjunct to confirm that all cells have normal peroxisome morphology and import peroxisomal matrix proteins.

Biochemical testing: Biochemical assays can determine definitively whether an individual has a peroxisomal biogenesis disorder, Zell weger syndrome spectrum (PBD, ZSS). ${ }^{23,24}$

The battery of biochemical analyses used to diagnose PBD include: plasma level of very long fatty acids (V LFCA), phytanic acid, plasmalogenes on erytrocite membrane, plasma/urine pipecolic acid and plasma/urine bile acids determination. The measurement of plasma very-long-chain fatty acid (V LCFA) concentrations is the most commonly used and most informative initial screen. Elevation of the plasma concentrations of $C 26: 0$ and C26:1 and the ratios of C24/C22 and C26/C22 is consistent with a defect in peroxisomal fatty acid metabolism. The degree of VLCFA plasma concentration elevation may vary, with a small percentage of individuals demonstrating only modest el evations. Biochemical abnormalities detected in blood and/ or urine should be confirmed in cultured fibroblasts.

\section{MOLECULAR GENETICS OF CHROMOSOMAL DISORDERS}

Chromosomes are complex bodies in cell nucleus as carriers of genes. While some diseases are due to genetic abnormalities 
acquired in a few cells during life, the term "genetic disease" most commonly refers to diseases present in all cells of the body and present since conception. Some genetic disorders are caused by chromosomal abnormalities due to errors in meiosis, the process which produces reproductive cells such as sperm and eggs. Other genetic changes may occur during the production of germ cells by the parent. O ne example is the triplet expansion repeat mutations which can cause fragile $X$ syndrome or Huntington's disease. ${ }^{24,31}$ Defective genes may also be inherited intact from the parents. In this case, the genetic disorder is known as a hereditary disease. This can often happen unexpectedly when two healthy carriers of a defective recessive gene reproduce.

Chromosomal abnormalities are disruptions in the normal chromosomal content of cell and are a major cause of genetic diseases in humans; some chromosomal abnormalities do not cause disease in carriers such as translocations or chromosomal inversions although they may lead to higher proportions of chromosomal disorder in child. A bnormal number of chromosomes or chromosome sets called aneuploidy may cause letal condition or give rise in genetic disorders. Furthermore the gain or loss of chromosome material may lead to genetic disorder (deletion, extra copy as trisomy). Chromosomal mutations produce changes in whole chromosomes (more than one gene) or in the number of chromosomes present.

\section{The Major Chromosomal Abnormalities}

The risk for chromosomal abnormalities increases with increasing maternal age, mainly because non-dysfunctional events in meiosis are more likely, and result in trisomies. To make it more complex the "mosaicism" must be added. A "mosaic" is a person with a combination of two cell lines with different karyotypes (normal and abnormal). When karyotyping is performed, multiple cells are analyzed to rule out this possibility. The mosaic condition is not as severe as the completely abnormal karyotype, and the features may not be as marked, and live births may be possible. Sometimes the mosaic's is confined to the placenta ("confined placental mosaicism").

A placenta with an abnormal karyotype (confined placental mosaicism) may lead to stillbirth, even though the fetus has a normal karyotype; conversely, a placenta with a normal karyotype may allow longer survival for a fetus with a chromosomal abnormality. Rarely, a translocation of part of one chromosome to another in the parent will be passed on to the child as a partial trisomy (such as $6 p+$ or $16 p+$ ) which may not be as severe as a complete trisomy.

The list of chromosomal abnormalities

- Trisomy 21 (extra chromosome 21): Down syndrome; incidence based upon maternal age, though translocation type is familial; features can include: epicanthal folds, brachycephaly, cardiac defects.
- Trisomy $18(47, X Y,+18)$ : Features include micrognathia, overlapping fingers, horseshoe kidney, rocker bottom feet, cardiac defects, diapragmatic hernia, omphalocele.

- Trisomy 13 (Patau Syndrome also called D-Syndrome): Features include microcephaly, cleft lip and/or palate, polydactyly, cardiac defects, holoprosencephaly.

- Trisomy 16: Seen in abortuses from first trimester. N ever liveborn.

- M onosomy X: Turner's syndrome $(45, X$ 0); can survive to adulthood; features include short stature, cystic hygroma of neck (leading to webbing), infertility, coarctation.

- Klinefelter's syndrome (XXY, a male with $2 X$ chromosomes); features include elongated lower body, gynecomastia, testicular atrophy (incidence: $1 / 500$ males)

- Triploidy: There is often a partial hydatidiform mole of placenta. Fetal features include 3-4 syndactyly, indented nasal bridge, small size.

- Idic 15 or isodicentric 15: Inverted duplication of chromosome 15 or tetrasomy 15.

- Jacobsen syndrome also called the terminal $11 q$ deletion disorder. This is a very rare disorder. Those affected have normal intelligence or mild mental retardation, with poor expressive language skills. M ost have a bleeding disorder.

- $X Y Y$ syndorm. $X Y Y$ boys are usually taller than their siblings. Like $X X Y$ boys and $X X X$ girls, they are somew hat more likely to have learning difficulties.

- Triple XXX syndrome. XXX girls tend to be tall and thin. They have a higher incidence of dyslexia.

The molecular chromosomal testing methods are available for prenatal diagnosis for detecting chromosomal microdel etions, duplications, translocation, complex rearrangements for full scale of disorders combining cytogenetic with fluorescence polymerase chain reaction. ${ }^{24,25} \mathrm{U}$ Itrasound precede to genetic testing and may be combined with biochemical screening 26,27

\section{TRIPLET RE PEAT SYNDROMES}

\section{Fragile X Syndrome}

Fragile $X$ syndrome, or Martin-Bell syndrome, is a genetic syndrome which results in a spectrum of characteristic physical, intellectual, emotional and behavioral features. It is the most common inherited cause of mental retardation. ${ }^{28}$ The syndrome is associated with the excessive repetition of a single trinucleotide gene sequence (CGG) on exon 1 FMR 1 gene located on X chromosome. ${ }^{29}$ In $99 \%$ of cases elongation of CGG triplets results in a failure to express the FM R-1 protein which is required for normal neural development. There are different forms of $F$ ragile $X$ syndrome which relate to the length of the repeated CGG sequence; normal (29-31 CG G repeats), intermediate or gray zone alleles (40-60 repeats) permutation (55-200 CGG repeats), full mutation (more than 200 CGG 
repeats), and mosaicizm (methylated more than $200 \mathrm{cgg}$ repeats). 29,30

The determination of triplets number is important for diagnosis oddiseased and carriers. The elongation is transmitted from mother to children. Beside meiotic unstability, full mutation FMR 1 gene show mitotic unstability which is the reason why cells in different tissues may have different number of CG triplets (mosaicism). In other $1 \%$ of fragileX syndrome individuals the disease is caused by deletion or point mutation in FM R 1 gene. Additional studies have revealed that on the expression of fragile $X$ syndrome is influenced by the rate of methylation of $C p G$ in promotor gene region. In individuals with full mutation and methylation of $C p G$ no transcription of gene and FM RP synthesis is present. In heal thy carriers F M RP protein is normally synthesized. FM R protein is potentially involved in $\mathrm{mRNA}$ processing within the cell. The connection between FM R P and mental disability is not known. Syndrome fragile $X$ chromosome is inherited by $M$ andelian low and expression of disease differs according to sex and number of $C G G$ repeats (type of mutation).

M olecular diagnosis is based on determination of CGG triplets in FM R 1 gene by polymerase chain reaction or Southern blot hybridization. Prenatal genetic testing is possible in DNA isolated from chorion villi cells after 12 weeks of pregnancy. 31,32 The analysis of point mutation and microdeletion present in $1 \%$ of diseased is available in only few special ized laboratories. In adults (carriers) FMRP may be analyzed by immunohistochemical method. ${ }^{33}$

Spinocerebellar ataxia (SCA) is a group of genetic disorders characterized by slowly progressive in coordination of gait and often associated with atrophy of cerebellum. ${ }^{34}$ SCA results in unsteady and clumsy motion of the body due to a failure of the fine coordination of muscle movements, along with other symptoms. The symptoms differs in individual patients according to type of genetic change. There are many types of spinocerebellar ataxia and about 30 different gene mutations have been found. One of the common genetic defects is an expansion of a CA G triplet repeat. In this way, it is similar to fragile- $X$ syndrome, Huntington disease and myotonic dystrophy, all of which exhibit a triplet repeat expansion of a gene. In the case of spinocerebellar ataxia I, the gene is SCA 1, found on chromosome 6 . (The protein product of the gene-called ataxin-1 varies in size, depending on the size of the CA G triplet repeat. $^{35}$

The main cause of the disease is el ongation of CA G triplets in coding region of SCA gene resulting in synthesis of nonfunctional proteins. The hereditary ataxias are categorized by mode of inheritance and causative gene or chromosomal locus. The hereditary ataxias can be inherited in an autosomal dominant, autosomal recessive, or X-linked manner. M olecular genetic testing using PCR or DNA chip technology is developed and used mainly for differential diagnosis of diseased individuals of adult age (Table 2 ). ${ }^{35}$

Huntington disease (HD) is an inherited, degenerative neurological disease that leads to dementia. The HD gene, whose mutation results in $\mathrm{H}$ untington disease, was mapped to chromosome 4 locus $4 p 16.3 .^{36}$ The mutation is a characteristic expansion of a CAG nucleotide triplet repeat in the DNA that codes for the protein huntingtin. A dditionally another mutation was found containing polygl utamin chain . M utated hungtinton protein form with some other proteins toxic nonsoluble accumulations in cell nuclei causing death of neurons and

Table 2: Main characteristics of $\mathrm{SCA}^{35,58}$

\begin{tabular}{|c|c|c|c|}
\hline SCA type & Incidence & Symptoms & DNA analysis \\
\hline SCA 1 (ATXN1) & $6-27 \%$ of all ADCA & $\begin{array}{l}\text { Hypermetric saccades, slow saccades, upper motor neuron } \\
\text { (note: saccades relates to eye movement) }\end{array}$ & CA G repeat, $6 p(A \operatorname{taxin} 1)$ \\
\hline SCA 2 (ATXN2) & $13-18 \%$ ADCAI & $\begin{array}{l}\text { Diminished velocity saccades are flexia (absence of neurologic } \\
\text { reflexes) }\end{array}$ & CA G repeat, $12 q$ \\
\hline SCA 3 (MJD) (ATXN3) & $23-36 \%$ A DCAI & $\begin{array}{l}\text { A lso called M achado-J oseph disease (M JD) Gaze-evoked } \\
\text { nystagmus (a rapid, involuntary, oscillatory motion of the } \\
\text { eyeball) upper motor neuron slow saccades }\end{array}$ & CA G repeat, $14 q$ \\
\hline SCA 6 (CACNA IA) & $10-30 \%$ ADCAIII & $\begin{array}{l}\text { D ownbeating nystagmus, positional vertigo symptoms can } \\
\text { appear for the first time as late as } 65 \text { years old. }\end{array}$ & $\begin{array}{l}\text { CA G repeat, 19p } \\
\text { Calcium channel gene }\end{array}$ \\
\hline SCA 7 (ATXN7) & ?ADCAII & M acular degeneration, upper neuron slow saccades & CA G repeat, $3 p$ (A taxin 7) \\
\hline $\operatorname{SCA} 8^{1}(\operatorname{IOSCA})$ & ADCAIII? & $\begin{array}{l}\text { Horizontal nystagmus (a rapid, involuntary, oscillatory motion } \\
\text { of the eyeball) }\end{array}$ & CTG repeat, $13 q$ \\
\hline SCA 10 (ATXN10) & ADCAIII & A taxia, seizures & $\begin{array}{l}\text { Chromosome } 22 q \\
\text { pentanucleotide repeat }\end{array}$ \\
\hline SCA 12 (PPP2R 2B) & ADCAI & $\begin{array}{l}\text { Head and hand tremor, akinesia (loss of normal motor } \\
\text { function, resulting in impaired muscle movement) }\end{array}$ & CA G repeat, $5 q$ \\
\hline SCA 17 (TBP) & ADCAI & & $\begin{array}{l}\text { CA G repeat, } 6 q \\
\text { TATA-binding protein }\end{array}$ \\
\hline
\end{tabular}


degeneration in some brain region. As the number of repeated triplets - CA G (cytosine, adenine, guanine) - increases, the age of onset in the patient decreases. Furthermore, because the unstable trinucleotide repeats can lengthen when passed from parent to child, the age of onset can decrease from one generation to the next. The diagnosis of Huntington disease is based on DNA analysis of CA G triplets in HD gene. Normal finding is 10-35 triplets, the finding of 39-120 triplets in one allele means that Huntington disease is confirmed. The borderline findings $35-38$ have to be follow ed as suspects. ${ }^{36,37}$

\section{GENETIC RISK DETERMINANTS OF CEREBRAL PALSY: NEW CHALLENGE IN FETAL BRAIN RESEARCH}

Cerebral palsy is the commonest cause of severe childhood disability of unknown etiology. A number of risk determinants have been elucidated in previous investigations of cerebral palsy by number of researchers among which indicators of inflammation and genetic changes were more closely related to at least a certain forms of this common, poorly understood, and intractable group of conditions.

The mechanisms involved are not well understood and may differ in very immature versus term infants. It might be speculated that both inflammation and genetic changes in general are involved in etiology of cerebral palsy by their presumably potential to encode an important group of CNS developmental proteins necessary for both early neural development and to establish cerebral function or are essential during early stages of growth of the immature CNS. Familial aggregation was described in some populations. ${ }^{1,38} \mathrm{H}$ owever it was shown that parents who have had one affected child have high risk of the recurrence in another child. ${ }^{39}$ From neuroimmaging studies it was suggested that most of the lesions potentially underlying $\mathrm{CP}$ are derived from the third trimester. ${ }^{40}$

The results of genome wide search in some affected families revealed close rel ationship for genetic markers located on from chromosome 2q24-25. ${ }^{41}$ On the contrary other studies showed no consistent overall phenotype segregation in the families with linkage to chromosome 2q24-25, compared with unlinked families. In addition, considerable inter and intra familial variation was seen due to complex gene vs environment and gene to gene interactions. $\mathrm{M} \mathrm{CH}$ ale and others have identified a family that segregates both ataxic $C P$ and ataxic displegia and have mapped the genetic locus responsible in this family to chromosome 9p12-q12. ${ }^{42}$

Recently Sylvain Hanein and others have identified six different mutations of SPG 15 locus on chromosome 14q23.3q24.2, which encodes a zinc-finger protein named spastizin, as potential genetic marker. ${ }^{43}$ Therefore the assessment of these and other candidate genes as GAD1 (the gene which codes glutamate decarboxylase, enzyme important for GABA production) may lead to better insights into the mechanisms involved in the differentiation of neuronal pathways and, in particular, those factors involved in motor function. ${ }^{44}$

Some of results suggests that these and other genes may prove to have temporal- or site-specific expression patterns within the developing brain and may only be essential during the relatively early stages of growth of the immature CNS. It al so seems likely that a proportion spastic cerebral palsy may be attributable to environmental factors that have an impact on the expression of genes at risk "in utero", where inflammation and cytokines my play an important role. ${ }^{45} 4 \mathrm{D}$ sonographic assessment of fetal facial expression and movement, semiquantitative score proposed by K urjak and cow orkers might make a progress in prenatal diagnosis of $C P .{ }^{46,47,48}$ The simultaneous identification of gene(s) involved in the etiology of $\mathrm{CP}$ will offer the possibility of prenatal/premarital testing to some families with children affected with the disorder.

\section{MOLECULAR GENETICS AS DIAGNOSTIC TOOL}

The advances in molecular biotechnology in last decade open new era in diagnosis of molecular and genetic mechanisms underlying in most inherited and/or genetic diseases. The confirmation of changes in chromosomes and genes is not important for diseased individuals only, but even more in preventive medicine and prenatal care. Therefore the focus will be on prenatal diagnosis which employs a variety of techniques to determine the health and condition of an unborn fetus. W ithout knowledge gained by prenatal diagnosis, there could be an untoward outcome for the fetus or the mother or both.

Specifically, prenatal diagnosis is beside detection of risk for inherited and genetically caused disease necessary for:

- $M$ anaging the remaining weeks of the pregnancy

- Determining the outcome of the pregnancy

- Planning for possible complications with the birth process

- Planning for problems that may occur in the newborn infant

- Deciding whether to continue the pregnancy

- Finding conditions that may affect future pregnancies.

There are a variety of non-invasive and invasive techniques available for prenatal diagnosis. Each of them can be applied only during specific time periods during the pregnancy for the greatest utility. Indications for prenatal diagnostic testing include: age of mother, D own syndrome in previous pregnancy or family, structural aberrations in previous pregnancies or in family members, autosomal genopaties, $\mathrm{X}$-linked genetic disorders, neuronal tube defects in previous pregnancies, mental retardation in family (linked to fragile $X$ ) present ultrasound suspicion, consanguinity, pathological finding in prenatal serum screening, other reasons (viral infection, radiation). The indications based on sonographic or M RI finding have even broaden the spectrum of prenatal genetic tests (Table 3$)^{49}$. The utilization of available methods depends in different part of the world not only on human, infrastructure or financial resources, but cultural, religious and other factors. 
Table 3: Examples of DNA microdeletion/duplication associated with anomalies based on prenatal US and reflecting brain/nervous diseases (modified from Ward) ${ }^{49}$

\begin{tabular}{lll}
\hline Microcephaly & Craniosynostosis & Micrognathia \\
\hline Deletion $1 p 36$ & Deletion $9 p$ (metopic) & Deletion $11 q$ \\
Deletion $3 p$ & Deletion $4 q$ & Deletion $13 q$ \\
Deletion $4 p$ & Deletion $11 q$ & Deletion $3 p$ \\
Deletion $18 p$ & Deletion $13 q$ & Deletion $4 p$ \\
Deletion $11 q$ & Deletion $18 q$ & Deletion $5 p$ \\
Deletion $13 q$ & & \\
Deletion $18 q$ & & \\
Deleltion $22 q 11.2$ & & \\
\hline
\end{tabular}

\section{Source of Samples for Prenatal Testing}

The most important factor for exact prenatal diagnosis of chromosomal as well as genetic disorders is good quality of cell sample obtained either by invasive or non-invasive techniques.

\section{Chorionic Villi Sampling (CVS)}

In this procedure, a catheter is passed via the vagina through the cervix and into the uterus to the developing placenta under ultrasound guidance. A Iternative approaches are transvaginal and transabdominal. The introduction of the catheter allows sampling of cells from the placental chorionic villi. These cells can then be analyzed by a variety of techniques. The most common test employed on cells obtained by CVS is chromosome analysis to determine the karyotype of the fetus. The cells can also be grown in culture for biochemical or molecular analysis. CVS can be relatively safely performed betw een 9.5 and 12.5 weeks gestation.

CV S has the disadvantage of being an invasive procedure, and it has a small but significant rate of morbidity for the fetus; this loss rate is about 0.5 to $1 \%$ and higher than for women undergoing amniocentesis. Rarely, CV S can be associated with limb defects in the fetus. The possibility of maternal $\mathrm{Rh}$ sensitization is present as well as the possibility that maternal blood cells from the developing placenta are sampled instead of fetal cells. The obtained material may be used for fluorescent in situ hybridization (FISH) short tandem repeats (STR), DNA analysis and some biochemical tests. ${ }^{36,50}$

A mniocentesis (transvaginal aspiration of amnionic fluid 15-20 weeks of pregnancy) is the most used method (risk below $0,5 \%$ ) for sample for all kind of analyses. The cells isolated from amnionic fluid are used for chromosomal and DNA analyses with or without previous cell culture.

Preconception-preimplantation diagnosis is another possibility and is applied in connection with in vitro fertilization (IVF) to make diagnosis at the gamete stage or performing the biopsy of one or two blastomeres by aspiration with micropipette. Preimplantation diagnosis is now offered as an alternative to conventional prenatal diagnosis in following cases: recessive or dominant hereditary disorders linked to chromosome $X$, monogenic disorders of autosomal inheritance (recessive or dominant) and the detection of translocations (couples who are carriers of chromosome abnormality of number or structure). The procedure require well trained personnel and equipment.

$M$ aternal blood sampling for fetal blood cells is a new noninvasive technique that makes use of the phenomenon of fetal blood cells gaining access to maternal circulation through the placental villi. Ordinarily, only a very small number of fetal cells enter the maternal circulation in this fashion. The fetal cells can be sorted out and analyzed by a variety of techniques (cell sorter) to look for particular DN A sequences, but without the risks that first two invasive procedures inherently have. Fluorescence in-situ hybridization (FISH) is one technique that can be applied to identify particular chromosomes of the fetal cells recovered from maternal blood and diagnose aneuploid conditions such as the trisomies and monosomy $X .^{51}$

The problem with this technique is that it is difficult to get as many fetal blood cells as needed. There may not be enough to reliably determine anomalies of the fetal karyotype or assay for other abnormalities.

The discovery of cell-free fetal DNA in maternal plasma by Dennis L 0 in 1999 outlined new potential s for non invasive prenatal diagnosis. ${ }^{52,53}$ The quantitative analysis of free fetal DNA showed that this can be made up as much as $6,2 \%$ of total DNA present in the maternal plasma. Fetal DNA release into maternal plasma has been shown to be a very early physiological phenomenon and circulating fetal DNA molecules (SRY gene) have been detected in the first trimester onwards. ${ }^{54,55} \mathrm{~A}$ majority of research groups use fetal DNA to detect diseases with recessive $X$-linked pattern of inheritance with female being carriers of the mutation, but healthy, while male are normal or affected by disease. Increased fetal DNA release have been found in preeclampsia and intrauterine growth restriction. Recently fetal RNA has been also found in maternal plasma. The both discoveries of maternal DNA and RNA have fastened the use of micro array based approaches and made feasible to rapidly generation of new circulating genetic markers.

\section{Analytical Techniques}

The technologies developed for the Human Genome Project, the recent surge of available DNA sequences resulting from it and the increasing pace of gene discoveries and characterization have all contributed to new technical platforms that have enhanced the spectrum of disorders that can be diagnosed prenataly. The importance of determining the disease-causing mutation or the informativeness of linked genetic markers before embarking upon a DN A -based prenatal diagnosis is, however, still emphasized. 
Fluorescence in situ hybridization (FISH) technologies provide increased resolution for the elucidation of structural chromosome abnormalities that cannot be resolved by more conventional cytogenetic analyses, including microdeletion syndromes, cryptic or subtle duplications and translocations, complex rearrangements involving many chromosomes, and marker chromosomes (Fig. 4. FISH technologies in molecular cytogenetic studies). Interphase FISH and the quantitative fluorescence polymerase chain reaction are efficient tools for the rapid prenatal diagnosis of selected aneuploidies, the latter being considered to be most cost-effective if analyses are performed on a large scale. There is some debate surrounding whether this approach should be employed as an adjunct to karyotyping or whether it should be used as a stand-alone test in selected groups of women.

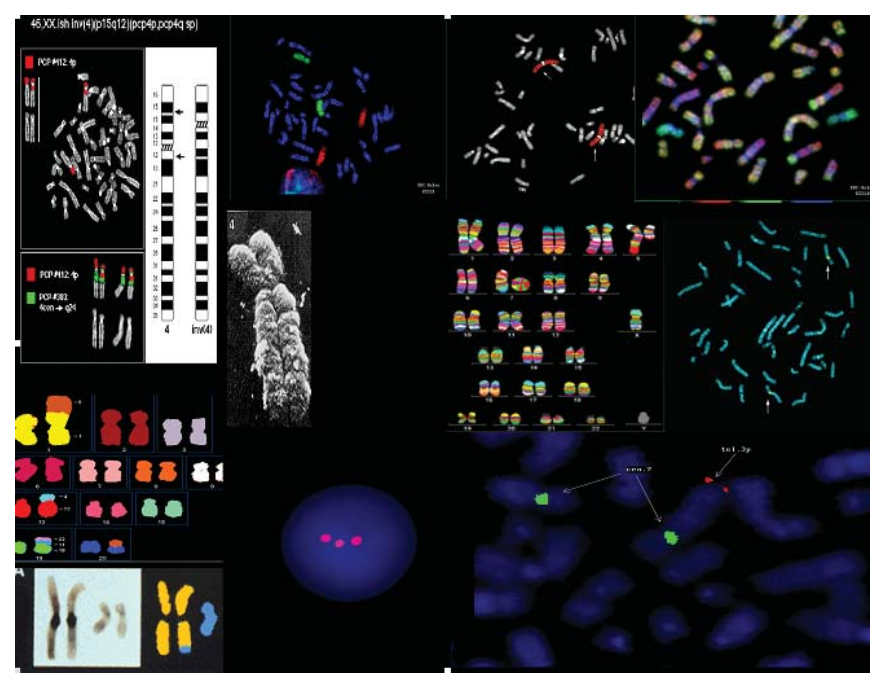

Fig. 4: FISH technologies for molecular cytogenetic studies

Interphase and metaphase FISH, either as a single probe analysis, or using multiple chromosome probes, can give reliable results in different clinical situations. It should be noted that there may be variation in probe signals both between slides (depending on age, quality, etc. of metaphase spreads) and within a slide. Where a del etion or a rearrangement is suspected, the signal on the normal chromosome is the best control of hybridisation efficiency and control probe additionaly provides an internal control for the efficiency of the FISH procedure.

Depending on the sensitivity and specificity of the probe and on the number of cells scored, the possibility of mosaicism should be considered, and comments made where appropriate. By using locus-specific probes at least 5 cells should be scored to confirm or exclude an abnormality. In multiprobe analysis: three cells per probe should be scored to confirm a normal signal pattern. Where an abnormal pattern is detected, confirmation is advisable. In prenatal interphase screening for aneuploidy signals should be countered in at least 30 cells for each probe set. A minimum 100 cells should be scored.
When hybridisation is not optimal, the test should be repeated. When a deletion or another rearrangement is suspected, the results must be confirmed with at least one other probe.

Results should preferably be followed up by karyotype analysis. This is essential when there are discrepancies between the expected laboratory findings, and the clinical referral.

B efore introducing interphase FISH as a diagnostic technique, staff need appropriate training on the type of samples to be analysed. Laboratories should set standards for classification of observations and interpretation of results and appropriate equipment is essential.

$M$ ore recently new method for fast identification of chromosomal abnormalities has been developed as high resolution array comparative genomic hybridization $(\mathrm{aCGH})$ which provide genome-wide analysis of chromosome copy number and structural change. The chip technology provide investigation of genetic causes associated with dysmorphic features, mental retardation, developmental delay, multiple congenital abnormalities. The commercial chip include more tha 40 abnormal ities including duplications and microdel etion regions. It is expected that evaluation of this technique will prove scientifically based evidence for named advantages.

DNA as analyte in genetic testing may be isolated from different biological material as peripheral blood, amnionic fluid, chorion villi, or maternal blood as free DNA. Todays techniques for gene mutation analysis are in general modification of polymerase chain reaction (PCR) technique where small quantity of DNA "in vitro "is multiplicated by under the activity of specific enzyme, the presence of primers and nucleotide mixture. The quantity of DNA obtained "in vitro" allow further the aplication of other analytical technologies for detection of mutation, deletion or other changes. Single strand conformation polymorphism (SSCP) method is used for detection of small mutations of gene and still is the most convenient method for detection of mutations of particular exons, as step before confirmation of mutation by sequencing. PCR in real time combine PCR and automatic multicolor fluorescence analysis of mutations and deletions allow fast analysis of number of DNA samples. ${ }^{31,32}$

Sequencing of DNA molecule allow determination of subsequent nucleotide $A$ (denin), $T$ (imin), G(uanin) and $\mathrm{C}$ (itozin) sequence. Multicolor, multichanell automatic sequencing with fluorescence emission developed in last five years made this procedure fast, efficient and safe.

The high throughput microarray technologies combined with robotics are the newest development in molecular genetic testing. The application of this technology and its different modifications allowed to analyse whole gene or more genes simultaneously which bring to clinicians new tool for rapid and safe diagnostic procedures. ${ }^{31,32}$ 
The advances in automatisation of analytical procedures and fast growing of test number bring to analyst the need for broad external quality assessment by certified proficiency testing bodies. In general, every laboratory which deliver test results for prenatal care should be recognized by certified referal laboratory for each test performed in this lab.

\section{THE RECOMMENDATION OF EUROPEAN COMMISSION (EC) FOR GENETIC TESTING}

The human genome project and other research activities on the identification of genes and their mutations causing diseases or inherited disorders resulted in the availability of molecular genetic tests and their clinical application on broader level. The EC has therefore formed in 2004 the working group of experts from different backgrounds with the aim to create the appropriate framew ork of regulation, information and education to guarantee a careful and beneficial application of new very promising technology. Consideration of the potential medical, psychological, social, legal and ethical consequences of genetic testing raises the question of how to ensure that the quality, safety and ethical application of genetic tests are guaranteed in Europe and around the world. The engagement of working group resulted with 25 recommendations in the form of report, to which a glossary is added thus allowing to non-experts the chance to better understanding the report and recommendations. ${ }^{56}$

The whole document is on web page of EU and in this chapter only basic overview is presented. The report is aimed to answer on most ethical, legal and social aspects of genetic testing: technologies used in research, diagnostics and clinical applications. Some of recommendations are briefly listed below.

When is genetic test as diagnostic or screening procedure recommended and who is competent for it performance?

Genetic testing can be performed on individuals as well as core or extended families. The term screening is usually reserved for systematic testing for inherited genome modifications of the members of defined populations or high-risk population sub-groups. As the relevant high-throughput technology improves and its cost decreases, it will al so be possi ble to screen the genome of individuals for a series of inherited variants.

Since the composition of an individual's chromosomes and DNA are fixed at fertilization (except in lymphocytes), most tests can be done at any stage of life, either before birth (preimplantation and prenatal diagnosis) or after birth (neonatal and adult screening and testing). N everthel ess, in most genetic testing centers the testing of children is, and will be, strictly limited to those cases in which a diagnosis is important for disease management or therapy.

Genetic testing is, or should be, carried out in specialized laboratories under the supervision of skilled laboratory technicians and trained geneticists. Tests are either performed using scientific protocols developed in-house, or by using diagnostic kits-standardized packages of components and instructions provided by manufacturers of diagnostics. For many genetic tests, diagnostic kits do not yet exist, so a large number of tests are still being carried out using protocols developed in the genetic testing laboratory itself, based on published scientific literature or other in-house protocols. Therefore external quality control is mandatory.

In general genetic test may be used for (i) diagnostic purpose, as (ii) screening procedure for prenatal, neonatal or carrier screening, or (iii) as predictive test. Predictive tests in this category cover a broad range of diseases and acquired conditions and can lead to the prediction of the future health status of an individual. Two different groups of predictive tests can be distinguished, based on the nature of the information resulting from them: presymptomatic tests for detection the presence of defects in certain specific genes or gene products which creates an almost 100\% risk of developing a particular disease later in life. Predisposition tests includes tests for other disorders in which defects in a single major gene are considered to increase substantially lifetime risk of devel oping the disease.

The genetic testing is a part of heal th system activities and all regulations on national level should be followed. The citizen should be informed about potentials and capacities for genetic tests. But the cross-border exchange of samples is recommended for continuous improvement of own knowledge and partnership within the region. The dialogue with public is necessary for education of broader public environment. On the other hand individual genetic information is part of the entirety of every individual's heal th information and does not a priori represent a separate category, although it may under certain circumstances (e.g. exceptionally high predictive information content). Thus, genetic exceptionalism is inappropriate. The broad range of recommendation concerns protection from discrimination and assurance to all equal and on time access to genetic testing. Recommendation on data protection: confidentiality, privacy and autonomy is important issue in the document. It is closely connected with informed consent. The recommendations promote the right of access to samples from diseased persons in the case of overriding interest for blood relatives. It is al lowed to use anonymous samples from diseased for research or development of new test. Recommendation on collections of human biological material and associated data will be coordinated in EU. N ew guidelines will be prepared for existing and new biobanks and biological resource centers. To national heal th authorities it is recommended to provide particular incentives to enable the development of pharmacogenetic tests. The regulatory framework for genetic testing will be further developed and for new tests safety, clinical validity and reliability should be recognized. EC will take measures to facilitate the availability of genetic testing for rare diseases as for more common diseases promoting regulatory framework on this topic. The consent procedures for children and vulnerable individuals will be strictly followed. For population screening 
program, education of public and new challenges EC will seek for more financial resources and appropriate medical environment.

\section{THE STATE MENT OF THE INTER NATIONAL ACADEMY OF PERINATAL MEDICINE ON ETHICAL CHALLENGES OF GENOMICS FOR PERINATAL MEDICINE}

International A cademy of Perinatal M edicine (IA PM) within the frame of Budapest meeting in 2007 bring up the statement of the most exteemed experts in the field of perinatal medicine from IA PM on ethical questions and challenges which arised recently in many countries due to new advances in diagnostic information and capacities. ${ }^{57}$ The statement clearly declare the autonomous wright of all pregnant women to chose and explore diagnostic possibilities and genomic information about the fetus depending on availability. The main role of competent perinatologist is to provide the pregnant women clinically important information in an understandable way and encourage her to share this information with her genetic partner.

The ethics of first- and second-trimester risk assessment currently provides a model for decision making with and by pregnant women about genomic assessment of the fetus taking into consideration scientifically based information about the risks and benefits of invasive diagnosis. The decision about the genomic assessment of the fetus made by pregnant women is an part of informed consent procedure.

A ccording the B udapest statement the policy for disclosure of the genomic assessment results including carrier status based on scientific evidence principles is that those informations should be disclosed routinely. The only exceptions are informations about later-onset conditions as well as results of uncertain or unknown clinical significance.

Furthermore the statement reveals strong ethical consensus about confidentiality of genomic information about the fetus.

Due to economic reasons and costs of patent based tests for fetal genomic assessment perinatologists should advocate for such a public policy in their national setting that reduce or eliminate such barriers. They will promote the need for more research in perinatal medicine. Finally according to this statement ethics is an essential component of genomc assessment of the fetus. Perinatologists have appropriate tools for implementation of new diagnostic resources within the frame of ethics of informed consent, pregnant women's authonomy, protection of professional integrity and fiduicary responsibility to pregnant and to fetal patients and the persons they will become. Perinatologists as profession have to be leader in advocacy for the allocation of healthcare resources in their countries thus allowing better access to fetal genomic assessment.

\section{REFERENCES}

1. Himmelmann, K Hagberg G, B eckung E, H agberg B , U vebrand $P$. The changing panorama of cerebral palsy in Swedeen. A cta Paediatrica 2005;94:287-94.

2. Jackson AP, et al. Identification of Microcephalin a protein implicated in determining the size of human brain. A m J Hum Genet 2005;71:136-42.

3. Jackson AP, et al. "Primary A utosomal Recessive M icrocephaly (M CPH 1) M aps to Chromosome 8p22-pter". A m J H um G enet 1998;63:541-46.

4. Evans PD, et al. M icrocephalin, a gene regulating brain size, continues to evolve adaptively in humans. Science 2005;309:1717-20.

5. Holm VA, Cassidy SB, Butler M G, et al Prader-W illi syndrome: consensus diagnostic criteria. Pediatrics 1993;91(2):398-402.

6. www.genetests.org.

7. A ngrist $M$, Jing $S, B$ olk St, B entley $K, N$ al lasamy $S, H$ al ushka M, Fox G, Chakravarti. Human GFRA 1: Cloning, mapping, genomic structure and evaluation as a candidate gene for Hirschsprung disease susceptibility. Genomics 1998;48:354-62.

8. Waye J S, Eng B, N owaczyk MJ. Prenatal diagnosis of SmithLemli-Opitz syndrome (SLOS) by DHCR 7 mutation analysis. Am J M ed Genet A 2007;143A (15):1799-801.

9. Lian G, Shen V. Cerebral developmental disorders. Curr Opin Pediatr 2006;18:614-20.

10. Groth $C$, Lardelli $M$. The structure and function of vertebrate fibroblast growth factor receptor 1. Int J Dev Biol 2003; 46(4):393-400.

11. Wilkie A O. Bad bones, absent smell, selfish testes: the pleiotropic consequences of human FGF receptor mutations. Cytokine Growth Factor Rev 2005;16(2):187-203.

12. RobinsoG odfrey $M$. The molecular genetics of $M$ arfan syndrome and related microfibrillopathies. J M ed G enet 2000;37(1):9-25.

13. Robinson PN, Booms P, Katzke $S$, et al. M utations of FBN 1 and genotype-phenotype correlations in $\mathrm{M}$ arfan syndrome and related fibrillinopathies. Hum M utat 2002;20(3):153-61.

14. Farrington-Rock C, Firestein M H, Bicknell LS, Superti-Furga $A, B$ acino CA, Cormier-Daire V , L e M errer $M$, et al. $M$ utations in two regions of FLNB result in atelosteogenesis I and III. Human M utation 2006;27:705-10.

15. Wagner T, W irth J, M eyer J, et al. A utosomal sex reversal and campomelic dysplasia are caused by mutations in and around the SRY -related gene SOX 9. Cell 1995;79(6):1111-20.

16. Joó J G, B eke A, Papp C, et al. N eural tube defects in the sample of genetic counselling. Prenat Diagn 2007;27(10): 912-21.

17. Kaneko KJ, Kohn M J, Liu C, Depamphilis M L. Transcription factor TEAD2 is involved in neural tube closure. Genesis 2007;45(9):577-87.

18. B adano, J ose L ,N orimasa M itsuma, Phil L B eales, $K$ atsanis $N$. The Ciliopathies: An Emerging Class of Human Genetic Disorders. A nnual Review of Genomics and Human Genetics 2006; 7:125-48.

19. Steinberg S, Raymond V G B ravermann, E Nancy, M oser W H. Peroxisome biogenesis disorders, Zellweger syndrome spectrum. Gene Reviews, www.gentests.org 
20. M ochel $F$, Grébille AG, B enachi $A, M$ artinovic J, Razavi $F$, Rabier D, Simon I, Boddaert N, Brunelle F, Sonigo P. Contribution of fetal M R imaging in the prenatal diagnosis of Zellweger syndrome. AJNR Am J Neuroradiol 2006;27(2): 333-36.

21. Rosewich H, Ohlenbusch A, Gärtner J. Genetic and clinical aspects of Zellweger spectrum patients with PEX 1 mutations. J M ed Genet 2005;42(9):e58.

22. Steinberg $S, C$ hen $L, W$ ei $L, M$ oser $A$, Moser $H$, Cutting $G$, B raverman N. The PEX Gene Screen: molecular diagnosis of peroxisome biogenesis disorders in the Zellweger syndrome spectrum. M ol G enet M etab 2004;83(3):252-63.

23. Steinberg SJ, Dodt G, Raymond GV, Braverman NE, M oser $A B, M$ oser HW. Peroxisome biogenesis disorders. Biochim Biophys A cta 2006;1763(12):1733-48.

24. Bui,TH, Blenow E, Nordenskjold M. Prenatal diagnosis: molecular genetics and cytogenetics. B est Pract R es Clin O bstet Gynecol 2002;5:629-43.

25. Capelle X, Schaaps JP, Foidart J M . New methods of prenatal screening for trisomy 21. Rev M ed Liege 2008;63(2):82-86.

26. Kagan KO, W right $D, B$ aker A, Sahota D, Nicolaides KH Screening for trisomy 21 by maternal age, fetal nuchal translucency thickness, free beta-human chorionic gonadotropin and pregnancy-associated plasma protein-A 2008; UItrasound Obstet Gynecol 31(6):618-24.

27. Cicero S, Bindra R, R embouskos G, Spencer K, N icolaides K H. Integrated ultrasound and biochemical screening for trisomy 21 using fetal nuchal translucency, absent fetal nasal bone, free beta-hCG and PAPP-A at 11 to 14 weeks. Prenat Diagn 2003;23(4):306-10.

28. Sherman S. "E pidemiology". Chapter 3 in F ragileX Syndrome, Diagnosis Treatment and R esearch. Hagerman RJ, Hagerman PJ (E ds): (3rd edn). J ohns H opkins U niversity Press: B al timore. 2002.

29. Hagerman RJ, Cronster A. Fragile $X$ syndrome: Diagnosis, treatment and research (2nd edm). Baltimore:J ohn Hopkins University Press 1996.

30. Cummings $\mathrm{C}$ J , Zoghbi HY . Trinucleotide repeats: mechanisms and pathophysiology. Annu Rev Genomics Hum Genet 2000;1:281-328.

31. Elles Rob. M olecular diagnosis of genetic diseases. Humana Press. Totowa, New J ersey, 2000.

32. M iny $P$, Tercanli S, H olzgreve W. Developments in laboratory techniques for prenatal diagnosis. Curr Opin Obstet Gynecol $2002 ; 14: 161-68$.

33. Hecimovic S, Barisic I, M uller A, Petkovic I, B aric I, Pavelic LK. Expand long PCR for fragile $X$ mutation detection. Clin Genet 1997;52:147-54.

34. Klockgether $\mathrm{T}$. The clinical diagnosis of autosomal dominant spinocerebellar ataxias. 2008; Cerebellum. A pril 12.

35. Brusco A, Gellera C, Cagnoli C, Saluto A, Castucci A, M ichielotto C, Fetoni V, M ariotti C, M igone N, Di Donato S, Taroni F. M olecular genetics of hereditary spinocerebellar ataxia: mutation analysis of spinocerebellar ataxia genes and CA G/CTG repeat expansion detection in 225 I talian families. A rch N eurol 2004;61(5):727-33.
36. A merican College of M edical Genetics:Hungtinton Disease Genetics Testing Working Group: Laboratory guidelines for Huntington disease genetic testing. Am J Hum Genet 1998;62:1243-48

37. Borovecki F, Lovrecic J, Zhou J, Jeong H, Rosas HD, Hersch $S M, K$ rainc D. Genome-wide expression profiling of human blood reveals biomarkers for Huntington's disease. www.pnas.org/cgi/doi/10.1073/pnas.0504921102.

38. Himmelmann K, Hagberg G, W iklund M I, Eak M N, Uvebrani $P$. Dyskinetic cerebral palsy: a population based study of childern born between 1991 and 1998. 2007; Developmental M edicine and Child Neurology 49:246-51.

39. Hemminki K, X injun L, Sundquist K, Sundquist]. High familial risk for cerebral palsy implicate partial heritable aethiology. Paediatric and Perinatal Epidemiology 2007;21:235-41.

40. Flodmark 0, Kraegeloh M ann I, Bax M, Tydeman C. Brain imaging studies of individuals with cerebral palsy. Dev M ed Child Neurol 2003;suppl:94:33-34.

41. M c Halle DP, M itchell S, Bundey S, M oynihan L, Capmbell DA, W oods CG, L euch NJ, M uller RF, M arkham A F. A gene for autosomal recessive spastic cerebral palsy maps to chromosome 2q24-25. A m J Hum G enet 1999;64:116-32.

42. $M$ CH ale DP, Jackson A P, Campbell DA, L evene M I, Corry P, Woods ${ }^{2,4}$, NJ L ench CG, M ueller RF, M arkham A F. A gene for ataxic cerebral palsy maps to chromosome 9p12-q12. European J Hum Genet 2000;8:267-72.

43. Sylvain Hanein, Elodie Martin,A mir Boukhris, Paula Byrne, Cyril Goizet, A bdelmajid H amri, A li B enomar, A lexandra Durr, Imed Feki, M ichael Hutchinson. Identification of the SPG 15 Gene Encoding Spastizin. The A merican Journal of Human Genetics 2008;82:992-1002.

44. Bertrand Fontaine, Claire-Sophie Davoine, Alexandra Durr, Carol ine Paternotte, I med Feki, J ean W iessenbach, J amile H azan and $A$ lexis B rice. A N ew L ocus for A utosomal Dominant Pure Spastic Paraplegia. The A merican J ournal of Human Genetics 2000;66:702-07.

45. Drews K Seremek A,Peinkowski J, Kaniak-Polcynska E. $M$ olecular aspects of intra-amniotic infection-short review. A rchives of Perinatal Medicine 2006;12:16-19.

46. Kurjak A, Stanojevic, M azuedi G, Carrera J M. The potential of four-dimanzional (4D) ultrasonogpraphy in the assessment of fetal awareness. 2005; Perinat M ed 33:46-53.

47. Kurjak $A$, A ndonotopo $W$, Hafner T, K upesic S, Solak M , V arga D. Normal standards for fetal neurobehaviour developments: longitudinal quantification by four-dimansional ultrasonography. J Perinat M ed 2006;34:56-65.

48. Kurjak A, Stanojevic M, A ndonotopo W, Scazzocchio-Duenas E, A zumedi G, Carrera J M. Fetal behavior assessmed in all three trimestry of normal pregnancy by four-dimensional ultrasonography. Croat M ed J 2005;46:772-80.

49. W ard K. Sonographic indications for molecular genetic testing. Donald School Journal of ultrasound in Obstetrics and Gynecology October-December 2007;(14):7-17.

50. Baric I, Stavljeniæ-Rukavina A. Racionalna dijagnostika nasljednih I prirodenih bolesti. Medicinska naklada Zagreb, 2005. 
51. Birch L, English CA, O'Donoghue K, Barigye O, Fisk NM, $K$ eer JT: A ccurate and robust quantification of circulating fetal and total DNA in maternal plasma from 5-41 weeks of gestation. Hum Genet 2005;117:243-48.

52. Leung TN, Zhang J, Lau TK, Hjelm NM, Lo Y M. M aternal plasma fetal DNA as marker for preterm labour. Lancet 1998;352:1904-05.

53. Lo Y M . Lau TK, Zhang J Leung TN, Chang A M, Hjelm N M. Increased fetal DNA concentration in the plasma of pregnant women carrying fetuses with trisomy 21 . Clin Chem 1999;45:1747-51.
54. Bianchi DW Circulating fetal DNA : its origin and diagnostic potential- a review. Placenta 2004;25(suppl A):593-S101.

55. A ymé S, M atthijs G, Soini S. ESHG W orking Party on Patenting and Licensing :Patenting and licensing in genetic testing: recommendations of the European Society of Human Genetics. Eur J Hum G enet 2008; (16 suppl 1):S10-19.

56. http://europa.eu.int/comm/research/science-society/ index_en.html.

57. www.íaperinatalmedicine.org.

58. Schmahmann JD. D isorders of the cerebellum: A taxia Dysmetria of thaught and the cerebellar affective syndrome. J Neuropsychiatry Clin N eurosci 2004; 16:367-78. 